\title{
Comparison of the prevalence of Toxocara spp. eggs in public parks soils in different seasons, from 2017 to 2018, Tehran Province, Iran
}

\author{
Vahid Raissi $^{\mathrm{a}}$, Vafa Saber ${ }^{\mathrm{b}}$, Mohammad zibaei $^{\mathrm{c}}$, Saeed Bahadory ${ }^{\mathrm{d}}$, Elham Akhlaghi ${ }^{\mathrm{e}}$, \\ Omid Raiesi $^{\mathrm{a}}$, Reza Aslani ${ }^{\mathrm{f}}$, Laya Shamsi ${ }^{\mathrm{g}}$, Ali Graili ${ }^{\mathrm{h}}$, Asmaa Ibrahim ${ }^{\mathrm{i}, \mathrm{j}, *}$ \\ ${ }^{a}$ Department of Medical Parasitology and Mycology, School of Public Health, Tehran University of Medical Sciences, Tehran, Iran \\ ${ }^{\mathrm{b}}$ Department of Microbiology Azad University Varamin, Pishva, Tehran, Iran \\ ${ }^{\mathrm{c}}$ Department of Parasitology and Mycology, School of Medicine, Alborz University of Medical Sciences, Karaj, Iran \\ ${ }^{\mathrm{d}}$ Department of Parasitology, Faculty of Medical Sciences, Tarbiat Modares University, Tehran, Iran \\ ${ }^{\mathrm{e}}$ Department of Parasitology and Mycology, School of Medicine, Kerman University of Medical Sciences, Kerman, Iran \\ ${ }^{\mathrm{f}}$ Medical University of Hamadan Reference Central Laboratories, Hamadan, Iran \\ ${ }^{\mathrm{g}}$ Department of Parasitology, Faculty of Veterinary Medicine, Urmia University, Urmia, Iran

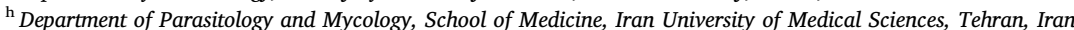 \\ ${ }^{\mathrm{i}}$ Diagnostic and Research Unit of Parasitic Diseases (DRUP), Department of Medical Parasitology, Kasr Al-Ainy Faculty of Medicine Cairo, University Cairo, Egypt \\ ${ }^{\mathrm{j}}$ Genetic Engineering and Biotechnology Research InstituteUniversity of Sadat CitySadat, Egypt
}

A R T I C L E I N F O

\section{Keywords:}

Prevalence

Toxocara spp

Eggs

Public parks

Soil

Seasons

Iran

\begin{abstract}
A B S T R A C T
Background and objectives: Toxocariasis is one of the most important pathogens transmitted to humans through the soil. Temperature $12-37^{\circ} \mathrm{C}$ provides the best conditions for infecting eggs to be transmitted to humans, dogs, and other hosts. This study is preliminary in order to detect Toxocara eggs in public park soils and to study the correlation between seasons and climate variation with contamination rate.

Methodology: A total of 1132 soil samples were collected over the course of the year, from 11 major parks. A centrifugal-floatation technique with the utilization of saturated sodium nitrate solution was used to examine the soil samples to recover Toxocara spp eggs.

Results: Out of 1132 samples collected from public park soils, 129 (11.39\%) samples were positive for Toxocara spp eggs, Laleh Park in south part showed the highest contamination rate. Contamination rate varied according to the site of parks, location with the highest rate in the south followed by center and the prevalence of eggs is high in spring and autumn without significant association. The prevalence of Toxocara spp eggs in soil associated significantly with Average temperature and rainfall ( $\mathrm{P}=0.04,0.001$ respectively).

Conclusion: According to our study findings, soils of the public parks in Tehran showed as one of the main sites for contamination with Toxocara spp eggs. The prevalence of soil contamination varied according to a climate of different seasons, spring and autumn climate such as temperature and rainfall rate were considered as optimal condition for eggs development and to survive.
\end{abstract}

\section{Introduction}

Soil-transmitted helminths (STH) are still one of the most significant public health issues. STH includes ascariasis, trichuriasis, ancylostomiasis, necatoriasis, strongyloidiasis, and toxocariasis. The prevalence rate of STH infections varies significantly due to variations in socioeconomic conditions; climate and other environmental factors. ${ }^{1}$ preparasitic stages of STH prefer wet climate seasons which help it to survive and increases in transmission, while dry climatic conditions kill infective stages on the soil surface. ${ }^{2}$ STHs infection was showed higher prevalence rate in rainy season compared to summer season. ${ }^{3,4}$ Toxocara spp are worldwide distributed zoonotic parasite of domestic animals which may lead to various form of the disease in paratenic hosts. According to the American Centers for Disease Control and Prevention (CDC), human Toxocariasis recognized as one of the top five neglected parasitic diseases. ${ }^{5}$ Toxocariasis in humans is caused by accidental ingestion of Toxocara ova from the environment. ${ }^{6,7}$ Public places such as parks, playgrounds, and sandboxes are the main areas of the helminthic

\footnotetext{
${ }^{*}$ Corresponding author. Diagnostic and Research Unit of Parasitic Diseases (DRUP), Department of Medical Parasitology, Kasr Al-Ainy Faculty of Medicine Cairo, University Cairo, Egypt.

E-mail address: chemistasmaain@gmail.com (A. Ibrahim).
} 


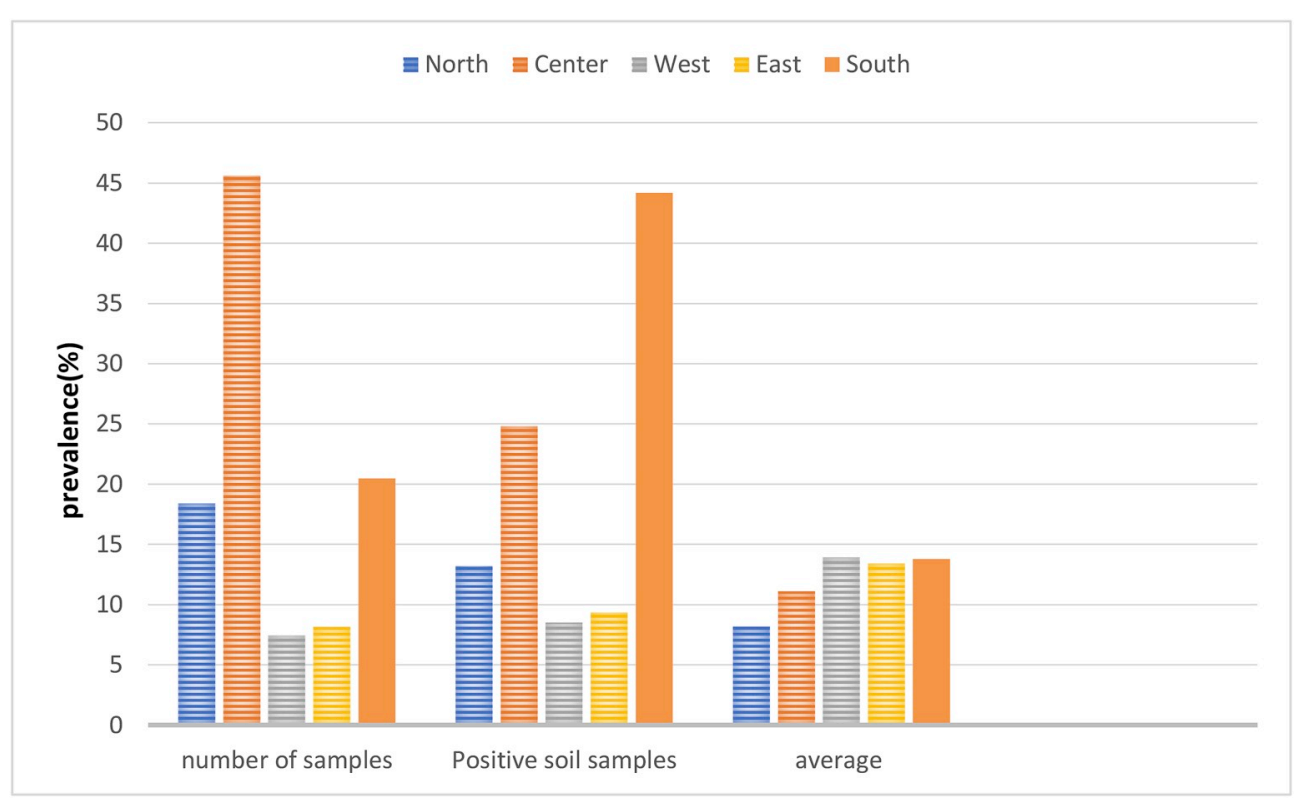

Fig. 1. Prevalence of Soil contamination with Toxocara spp egg in public parks, according to different park location in Tehran.

eggs transmission because of those areas recognized as the most common places for pets walking and erratic dogs and cats. ${ }^{8}$ The detection of Toxocara eggs in public soils have been reported in last studies in different parts of Iran, the condition of soil contamination in Tehran is not precisely known; also the correlation of seasonal variation with the prevalence of Toxocariasis in soil has not been detected. Thus, the current study was performed to determine the prevalence rate of Toxocara eggs in the public park soils in Tehran Province, Iran and study the effect of season variation and climate on the prevalence of Toxocara eggs in public soil.

\section{Materials and methods}

\subsection{Study region}

Tehran $\left(35^{\circ} 41^{\prime} 21^{\prime \prime} \mathrm{N} 51^{\circ} 23^{\prime} 20^{\prime \prime} \mathrm{E}\right)$ is the capital of Iran and Tehran Province (Fig. 1). With a population of around 8.4 million in the city as a most populous city in Iran and western Asia. Tehran has a cold, semiarid climate and a Mediterranean rain pattern which has about $300-305 \mathrm{~mm}$ of annual rainfall. Since the difference between altitudes in different parts of Tehran is significant, the weather in the mountainous north is much colder than the southern part of Tehran. Also, rainfall and humidity will be different. Seasonal changes in Tehran are very tangible. Summer is long, warm and dry, and rain is low, but it can make the heat more durable due to its low relative humidity. Temperatures average are between 90 and $106^{\circ} \mathrm{F}$, that it can drop to $14^{\circ} \mathrm{C}$ in the mountainous north of the city at night. July and June are the hottest months, with an average temperature between $91^{\circ} \mathrm{F}$ and $100^{\circ} \mathrm{F}$, and the coldest is January when the temperature varies from $23^{\circ} \mathrm{F}$ to $34^{\circ} \mathrm{F}$.

\subsection{Samples collection and soil recovery}

A total of 1132 soil samples were collected seasonally (every three months) from 11 major parks were selected based on factors such as municipal district, park area size and population traffic flow (from 02 October 2017 to 16 September 2018). Sampling was carried out randomly from every 50 steps and $10 \mathrm{~g}$ from of $3-5 \mathrm{~cm}$ ground depth which eventually includes $500 \mathrm{~g}$ of each area then the samples were thoroughly mixed and placed in sealed and labeled plastic baggage and transported to the laboratory. The soil samples were dried at room temperature for 2-3 days and passed through a $150 \mu \mathrm{m}$ mesh sieve.

\subsection{Detection of Toxocara spp eggs}

To recover Toxocara spp. eggs, the soil samples were examined by a centrifugal-floatation technique with the utilization of saturated sodium nitrate solution. Briefly, $20 \mathrm{~g}$ of the soil sample was placed in an associate Erlenmeyer's flask containing $50 \mathrm{ml}$ of $5 \% \mathrm{NaOH}$ (Merck, Germany) mixed and left for $1 \mathrm{~h}$ to separate eggs from the soil. The samples were then vortexed for $10 \mathrm{~min}$; the suspension was transferred to falcon tube and centrifuged at $1500 \mathrm{rpm}$ for $3 \mathrm{~min}$. The supernatant was discarded and saturated NaNO3 (Merck, Germany) with a selected gravity of 1.30 was added and centrifuged once more at $1500 \mathrm{rpm}$ for $3 \mathrm{~min}$. Finally, the Na-NO3 was superimposed on the tube to form cartilage and a coverslip was overlaid. After $30 \mathrm{~min}$, the coverslip was transferred onto a microscopic slide. The preparations were evaluated for the presence of Toxocara spp. eggs below the light microscope at $100 \times$ and $400 \times$ magnification. Furthermore, Positive samples were also randomly examined by formalin-ether method (In more than $90 \%$ of the random samples with both techniques were positive). Supported the size and morphology, the parasites were indicated as Toxocara spp. eggs. Data analysis was done through SPSS, statistical software version 20.

\subsection{Statistical analysis}

Analysis of data on the relationship between seasonal variations and parasitic load changes in soils was evaluation using SPSS version 20 software and chi-square test. Probability $(\mathrm{P})$ values of less than 0.05 were considered to be statistically significant $(P<0.05)$.

\section{Results}

After examining all sample of eleven parks, according to geographical area, it was shown that the contamination rate was variable, so that the Daneshjoo and Chitgar park from the center and west of the city have the least pollution $(3.9 \%)$ and the most rate related to the Laleh park from center of the city (Table 1). Regarding of embryonated eggs, the total number of positive specimens was found to be 129 $(11.39 \%)$. 
Table 1

Number of positive samples in different types of parks.

\begin{tabular}{|c|c|c|c|c|c|c|}
\hline & Location in the city & Number of samples & Positive soil samples(N) & Percent (\%) & Prevalence Ratio & $\mathrm{P}$-value \\
\hline Mellat & North & 112 & 10 & 7.75 & 1 & \\
\hline Chess & North & 96 & 7 & 5.43 & 0.6 & \\
\hline Shahr & Center & 128 & 11 & 8.52 & 0.7 & \\
\hline Daneshjoo & Center & 56 & 5 & 3.9 & 0.75 & \\
\hline Abrisham & Center & 84 & 9 & 7.0 & 0.9 & \\
\hline Laleh & Center & 168 & 22 & 17.05 & 1.3 & \\
\hline Saei & Center & 80 & 10 & 7.75 & 0.95 & \\
\hline Piroozi & East & 92 & 12 & 10.75 & 0.8 & \\
\hline Chitgar & West & 84 & 11 & 8.5 & 0.65 & \\
\hline Besat & South & 124 & 20 & 15.5 & 1.7 & \\
\hline Bahman & South & 108 & 12 & 10.75 & 1.2 & \\
\hline Total & & 1132 & 129 & 100 & & 0.055 \\
\hline
\end{tabular}

Table 2

Separation of positive samples by season.

\begin{tabular}{|c|c|c|c|c|}
\hline & Spring & Summer & Autumn & Winter \\
\hline Mellat & 4 & 2 & 3 & 1 \\
\hline Chess & 3 & 2 & 2 & 0 \\
\hline Shahr & 4 & 2 & 4 & 1 \\
\hline Daneshjoo & 3 & 1 & 1 & 0 \\
\hline Abrisham & 3 & 1 & 4 & 1 \\
\hline Laleh & 9 & 3 & 7 & 3 \\
\hline Saei & 3 & 2 & 4 & 2 \\
\hline Piroozi & 4 & 2 & 5 & 1 \\
\hline Chitgar & 5 & 2 & 2 & 2 \\
\hline Besat & 8 & 4 & 6 & 2 \\
\hline Bahman & 3 & 2 & 4 & 3 \\
\hline Total positive & $48(37.2 \%)$ & $23(17.8 \%)$ & $42(32.6 \%)$ & $16(12.4 \%)$ \\
\hline Total sample & $321(28.36 \%)$ & $266(23.50 \%)$ & 347 (30.65\%) & $198(17.49 \%)$ \\
\hline Prevalence ratio & 1 & 0.7 & 1.1 & 0.67 \\
\hline P-value & & & & 0.086 \\
\hline
\end{tabular}

\subsection{Seasonal soil contamination with Toxocara spp egg}

Soil samples had the highest of contamination in the spring (37.2\%), and on the other hand, we detect the lowest pollution in winter $(12.4 \%)$. The examined soil samples in the autumn and summer season had shown the $32.6 \%$ and $17.8 \%$ of contamination respectively. Details of soil contamination data by season are shown in Table 2 and Fig. 2.

Tables 3 and 4 show that the highest prevalence of soil contamination was reported with an average temperature of $12.33^{\circ} \mathrm{C}$ and an average rainfall of $16.66 \mathrm{~mm}$ results showed that the highest soil contamination was in autumn (30.65\%).

By analyzing the correlation between the rate of Toxocara spp eggs contamination in the parks and the sampling season, it showed that there was no significant relationship between them and this relationship is statistically meaningless. Based on the type of environment, we divided the samples into four categories: garden, garbage, grass and

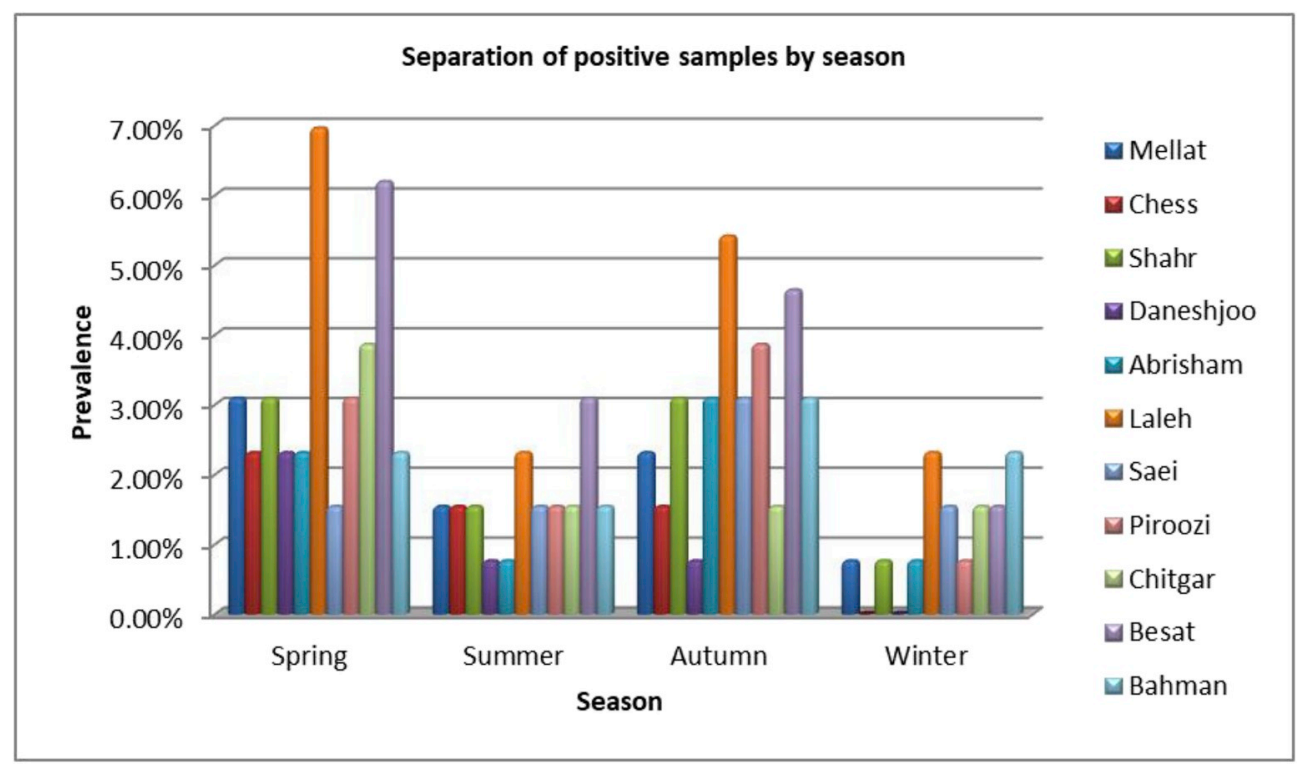

Fig. 2. Mean prevalence of Soil contamination with Toxocara spp egg in public parks of Tehran, Iran. 
Table 3

Toxocara spp egg prevalence in soil samples based on the average temperature of different season (www.holiday-weather.com).

\begin{tabular}{llllll}
\hline & Spring & Summer & Autumn & Winter & p-value \\
\hline Prevalens (\%) & $28.36 \%$ & $23.50 \%$ & $30.65 \%$ & $17.49 \%$ & $\mathbf{0 . 0 4 0}$ \\
Average temperature $\left({ }^{\circ} \mathrm{C}(\right.$ & $22.66^{\circ} \mathrm{C}$ & $28.66^{\circ} \mathrm{C}$ & $12.33^{\circ} \mathrm{C}$ & $7^{\circ} \mathrm{C}$ & \\
\hline
\end{tabular}

Table 4

Toxocara spp egg prevalence in soil samples based on the average rainfall of different season (www.holiday-weather.com).

\begin{tabular}{llllll}
\hline & Spring & Summer & Autumn & Winter & p-value \\
\hline Prevalens (\%) & $28.36 \%$ & $23.50 \%$ & $30.65 \%$ & $17.49 \%$ & $\mathbf{0 . 0 0 1}$ \\
Average rainfall (mm & $13.33 \mathrm{~mm}$ & $10 \mathrm{~mm}$ & $16.66 \mathrm{~mm}$ & $33.33 \mathrm{~mm}$ & \\
\hline
\end{tabular}

children playgrounds. The highest amount of contamination was in the garden area with a rate of $39.54 \%$ and the lowest amount was related to garbage, which results are proportional to the number of samples from each section. (Table 5). Contamination rate of garden areas is considered statistically significant ( $\mathrm{p}$-value $<0.05$ ).

\section{Discussion}

In this current study, we investigated the prevalence of Toxocariasis in public park soils among 11 major parks in Tehran province, Iran using the flotation technique. The recovery of Toxocara eggs from soil samples of the public parks relying on several potential environmental factors such as temperature, humidity, sunlight, the source and site of soil samples, and the diagnostic technique. ${ }^{9}$ Toxocara spp eggs need time in suitable environmental conditions to be infectious to paratenic hosts. ${ }^{10}$ Our study showed that the contamination rate with Toxocara spp. eggs of $11.39 \%$ (129/1132 soil samples) in soil samples collected from public parks in 11 major different locations of Tehran. In agreement with ${ }^{11}$ who reported that the prevalence of Toxocara spp. eggs in public park soils in Tehran 10\%. In contrast with other studies in different parts in Iran has been reported, such in Abadan $(29.2 \%)^{12}$; Khoramabad $22.2 \%{ }^{13}$; and Shiraz $6.3 \% .{ }^{14}$ Furthermore, On average, the prevalence of toxocariasis in Iran has been less than $16 \%$ in humans and about $20 \%$ in animals in various studies. ${ }^{15}$ Our study findings showed that the prevalence of soil contamination with Toxocara spp. eggs varied with site and location of the soil samples, Laleh showed the highest soil contamination rate followed by Besat then Bahman (17.05\%, $15.5 \%$, and $10.75 \%$ respectively) this difference in prevalence with the site not statically significant. The prevalence rate of soil contamination showed that the prevalence is high in South part followed by the center, In agreement with ${ }^{16}$ who reported high prevalence of Toxocara eggs in Stara Zagora region South Bulgaria. Public parks and playgrounds are more susceptible to pets and stray animals and cause infection transmission to human and uninfected animals. Pets are attended to public places to defecate, thereby contaminating the soil. Public parks were reported as the most contaminated place with
Toxocara eggs than the playgrounds. ${ }^{13,17}$ Our findings showed that the contamination rate is higher in the garden (39.54\%) followed by grass (27.9\%). Toxocara contamination prevalence varied over the course of the year, infection rate may vary depending on the season. ${ }^{18,19}$ In this study the prevalence of Toxocara eggs detection in soil carried with seasons with higher prevalence in spring (37.2\%), autumn (32.6\%), In agreement with Some researchers who noticed that the presence of Toxocara eggs in sandpits located in Japan public parks, reporting a higher prevalence of eggs recovering during the autumn, spring and early summer. ${ }^{20}$ In addition to in other countries, the highest egg prevalence have detected in these seasons ${ }^{21,22}$ ) which is may be connected with the reproductive period of the definitive hosts in these seasons. In contrast with $^{23}$ who reported the period of higher prevalence of egg recovered peak was during the winter. Temperatures and rainfall were associated factors with eggs survival. Our study was conducted when temperatures are varied from 7 to $28.66^{\circ} \mathrm{C}$ in Tehran Province Iran with high prevalence in temperature between 12.33 and $22.66^{\circ} \mathrm{C}$, temperature showed significant association with Toxocara egg prevalence $(\mathrm{P}=0.04)$. Previous studies have reported that the temperature ranges from 23 to $30^{\circ} \mathrm{C}$ is the optimal temperature for Toxocara egg development in soil. ${ }^{24}$ Rainfall rate in our study showed significant association with Toxocara egg in soil $(\mathrm{P}=0.001)$, low rate of rainfall is favorable for eggs survival and contamination rate, the best rate reported at $13.33-16.66 \mathrm{~mm}$ rather than high rainfall in winter. In agreement with ${ }^{25}$ who reported that the low rainfall rate was favored for the eggs extinction.

\section{Conclusion}

To conclude, the current study revealed that the contamination rate of Public Park soils in Tehran with Toxocara spp. eggs (11.39\%). According to our data, there is a relatively high prevalence of Toxocara eggs in spring and autumn due to variation in temperature and rainfall. It should prevent the entrance of domestic animals (dogs and cats) into parks due to the presence of contamination in the area's soils and provide people with the necessary knowledge about toxocariasis-infected pathogens.

\section{Author's contribution}

Study concept and design: VR, VS, MZ, AI, acquisition of data: SB, EA, OR, RA,VS, analysis and interpretation: VR, AI, LS,AG.

\section{Ethical statement}

All steps are from sampling to analysis of results according to approved and standard protocols.

\section{Declaration of competing interest}

The authors and coauthors declare that they have no conflict of interest that affects this study.

Table 5

Number of positive samples based on the type of environment.

\begin{tabular}{|c|c|c|c|c|}
\hline Environment & $\begin{array}{l}\text { Number of samples } \\
\mathrm{N}(\%)\end{array}$ & $\begin{array}{l}\text { Number of positive samples } \\
\mathrm{N}(\%)\end{array}$ & Prevalence Ratio & P-value \\
\hline Garden & 406 (35.87\%) & $51(39.54 \%)$ & 1 & \\
\hline Garbage & $84(7.43 \%)$ & 17 (13.18\%) & 2.08 & \\
\hline Children playground & $243(21.46 \%)$ & 25 (19.38\%) & 0.88 & \\
\hline Total & $1132(100)$ & $129(100)$ & & 0.166 \\
\hline
\end{tabular}




\section{Acknowledgments}

The authors express their appreciation and appreciation to all those who have contributed to this project.

\section{References}

1. World Health Organization, Framework for Control and Prevention of SoilTransmitted Helminthiases in the WHO European Region 2016-2020WHO Regional Office for EuropeUN City, Marmorvej 51 DK-2100 Copenhagen $\emptyset$, Denmark.

2. Weaver HJ, Hawdon JM, Hoberg EP. Soil-transmitted helminthiases: Implications of climate change and human behavior. Trends Parasitol. 2010;26(12):573-581.

3. Choudhary L, Prabhawati Sinha KP. Seasonal prevalence of soil transmitted helminths in the population of Kosi Region of North Bihar. Flora Fauna. 2015;21(1):9-14.

4. Avhad SB, Wahule VK, Hiware CJ. Effect of climate factors on the prevalence of intestinal helminths from Aurangabad district (MS), India. Int J Basic Appl Res. 2012;2(2):49-55.

5. Centers for Disease Control and Prevention. http://www.cdc.gov/parasites/ toxocariasis/ Accessed 1 May 2017.

6. Macpherson CN. The epidemiology and public health importance of toxocariasis: a zoonosis of global importance. Int J Parasitol. 2013 Aug;43(12-13):999-1008.

7. Traversa D, Frangipane diRegalbono A, Di Cesare A, La Torre F, Drake J, Pietrobelli M. Environmental contamination by canine geohelminths. Parasites Vectors. $2014 \mathrm{Feb}$ $13 ; 7: 67$.

8. B $^{3}$ aszkowska J, Góralska K, Wójcik A, Kurnatowski P, Szwabe K. Presence of Toxocara spp. eggs in children's recreation areas with varying degrees of access for animals. Ann Agric Environ Med. 2015;22(1):23-27.

9. Cardillo NM, Santillan G, Altcheh J, et al. Toxocariasis in Argentina: Historical Review. III Pan American Congress of Zoonoses. VIII Argentine Congress of Zoonoses; June 4-6. 2014; 2014 (La Plata- Buenos Aires).

10. Maraghi S, Mazhab Jafari K, Sadjjadi SM, Latifi SM, Zibaei M. Study on the contamination of Abadan public parks soil with Toxocara spp. eggs. J Environ Health Sci Eng. 2014;12:86

11. Khazan H, Khazaei M, Tabaee SS, et al. Prevalence of Toxocara spp. eggs in public parks in Tehran city, Iran. Iran J Parasitol. 2012;7:38-42.

12. Sharif M, Mazhab Jafari K, Sadjjadi SM, et al. Study on the contamination of Abadan public parks soil with Toxocara spp. Eggs. J Environ Health Sci Engin. 2014;12:86.

13. Zibaei M, Abdollahpour F, Birjandi M, Firoozeh F. Soil contamination with Toxocara spp. eggs in the public parks from three areas of Khorram Abad, Iran. Nepal Med Coll J. 2010;12:63-65.

14. Motazedian H, Mehrabani D, Tabatabaee S, Pakniat A, Tavalali M. Preva-lence of helminth ova in soil samples from public places in Shiraz. East Mediterr Health J. 2006;12:562.

15. Raissi V, Sohrabi Z, Getso M, et al. Risk factors and prevalence of Toxocarasis in pregnant women and diabetic patients compared to healthy adults in ilam province. EXCLI Journal. 2018;17:983-988.

16. Georgieva D, Kirkova Z, Ivanov A, et al. [Induced morbidity in children. Parasitological study of the children's playgrounds of Stara Zagora. Pediatria. 2005;45(1):23-25.

17. Habluetzel A, Traldi G, Ruggieri S, et al. An estimation of Toxocara canis prevalence in dogs, environmental egg contamination and risk of human infection in Marche region of Italy. Vet Parasitol. 2003;2561:1-11.

18. Kroten A, Toczylowski K, Kiziewicz B, Oldak E, Sulik A. Environmental contamination with Toxocara eggs and seroprevalence of toxocariasis in children of northeastern Poland. Parasitol Res. 2016;115:205-209.

19. Mizgajska-Wiktor H, Jarosz W, Fogt-Wyrwas R, Drzewiecka A. Distribution and dynamics of soil contamination with Toxocara canis and Toxocara cati eggs in Poland and prevention measures proposed after 20 years of study. Vet Parasitol. 2017;234:1-9

20. Shimizu T. Prevalence of Toxocara eggs in sandpits in Tokushima outskirts. J Vet Med Sci. 1993;55:807-811.

21. Uga S, Kataoka N. Measures to control Toxocara egg contamination in sandpits of public parks. Am J Trop Med Hyg. 1995;52:21-24.

22. Avcioglu H, Burgu A. Seasonal prevalence of Toxocara ova in soil samples from public parks in Ankara, Turkey. Vector Borne Zoonotic Dis. 2008 Jun;8(3):345-350.

23. Nijsse R, Mughini-Gras L, Wagenaar JA, Ploeger HW. Recurrent patent infections with Toxocara canis in household dogs older than six months: a prospective study. Parasites Vectors. 2016;9:531.

24. Rocha S, Pinto RMF, Floriano AP, et al. Environmental analyses of the parasitic profilefound in the sandy soil from the Santos municipality beaches, SP, Brazil. Revistado Instituto de Medicina Tropical de São Paulo; 2011:277-281.

25. Mizgajska H, Rejmenciak A. Rozróznianie jaj T. canis i T. cati -pasozytówpsa i kota. Wiad Parazytol. 1997;43:435-439 (Differentiation of T. canis and T. catieggs parasites of dog and cat). 